\title{
Perspectives of vaccination in Italy: adolescents and parental consent
}

\author{
Perspectivas sobre vacinação na Itália: \\ adolescentes e consentimento dos pais
}

Perspectiva de la vacunación en Italia: adolescentes y consentimiento parental

Andrea Cioffi 1

doi: 10.1590/0102-311X00195519

In July 2017, Italy introduced a national law extending the number of mandatory vaccines from four to ten for all residents aged between 0 and 16 years 1 . The final list included mandatory vaccination against tetanus, hepatitis B, polio, diphtheria, Haemophilus influenzae type B, varicella, pertussis, and measles-mumps-rubella (MMR).

This law was promulgated in response to a worrying decrease in vaccination coverage that occurred in Italy from 2012 to 2016 2. Between 2012 and 2014, vaccine coverage decreased dangerously in the country, reflecting an exponential increase in vaccine hesitancy 3; in 2015, Italy was one of the countries with the lowest levels of vaccine confidence in the world 4 . Despite the efforts of European health authorities, Italy, as well as other European countries, witnessed a growing vaccine hesitancy between 2015 and 2016 5,6. None of the four vaccines that were mandatory in 2016 reached the $95 \%$ coverage that guarantees the "herd immunity" 7 . For example, in the same year, vaccination coverage for the second dose of measles-containing vaccine was below 84\% in Italy and other European countries 8 .

The new Italian law obliges all parents to vaccinate their children; if they do not comply with the imposed measures, children cannot be admitted to the school system from childcare to secondary school. From the beginning of 2018, an immediate increase in vaccine coverage testified the positive impact of the applied regulation ${ }^{9}$. A few months after Law $n .119$ came into force, the Italian National Institute of Health confirmed that the national immunization coverage of the hexavalent vaccine (against tetanus, diphtheria, pertussis, poliomyelitis, hepatitis B, and $H$. influenzae B) had reached $95 \%$ (goal for herd immunity) 10.

Despite its excellent results, this law immediately sparked criticisms - from scientists - mainly based on the alleged lack of safety of vaccines 11.

Many anti-vax conspiracy theories have spread throughout Italy, among which a major one is the lack of safety of vaccines, which could be related to certain mental illnesses. Studies on this subject, often cited by anti-vaccination organizations, present numerous limitations (underlined by the authors themselves) and fail in correlating vaccines and certain diseases; rather, they present solely a temporal association between vaccination and the development of some pathological conditions 12 . They also often cite Wakefield et al. 13, a retracted article that suggested a correlation between vaccines and autism. For campaigning, anti-vax movements apply studies that hypothesize an association between vaccines adjuvants and the occurrence of neuroinflammation or autoimmune diseases 14,15 .
1 Sapienza University of Rome, Rome, Italy.

Correspondence A. Cioffi Sapienza University of Rome. Viale Regina Elena 336, Rome - 00161, Italy. andrea.cioffi@uniroma 1.it 
Naturally, international scientific literature attests that vaccines are significantly beneficial and present few and rare risks 16.

A widespread belief among people that sympathizes with anti-vaccine movements is that vaccination campaigns serve as a tool to enrich pharmaceutical companies 17 . Such theory ignores the increasing costs, for the National Health System, associated with morbidity and mortality resulting from serious difficult-to-treat infections, which would be easily prevented by vaccination.

There is no evidence that tests performed prior to vaccination could predict adverse reactions to vaccines. Yet, anti-vax movements, supported by the Italian Association of Consumer Rights Protection (CODACONS), requested pre-immunization allergy tests 18 .

In Italy, some representatives of the scientific community also support the anti-vaccination movement. An Italian doctor, for example, was removed from the National Medicine Board for spreading ideas contrasting evidence-based medicines in the vaccine field; precisely, he stated that there is no point in vaccinating infants for hepatitis B and tetanus 19 .

Anti-vax movements strongly believe herd immunity to be a myth. This theory claims that believing that vaccines can induce herd immunity is baseless, and that mass vaccination cannot eradicate infectious diseases 20. The propagation of anti-vax theories led the Italian National Institute of Health to disclosure an informative document, defining myths and truths regarding vaccinations 21.

Despite the total lack of foundation in these theories - which commonly apply scientific studies only to misinterpret them -, anti-vax movements are widespread in Italy, as well as in the world. Such movements pose a risk to morbidity and mortality levels related to infectious diseases, with important socioeconomic consequences 22 .

In 2007, a public health policy experiment conducted in Veneto (an Italian region with 4 million inhabitants) suspended mandatory childhood vaccination against polio, hepatitis B, tetanus, and diphtheria. The Ministry of Health opposed to the region political choice; yet, a great amount of the public opinion and some representatives of the Italian community of pediatrics praised and supported the legislation. This public health policy decreased by $5 \%$ the immunization coverage of polio vaccine from 2006 to $2016^{23}$, showing that, in countries with a strong anti-vaccine sentiment, suspending compulsory vaccination is not an optimal choice.

The debate on vaccines in Italy has never addressed the issue of early adolescents (from 10 years old) wanting to get vaccinated without parents' consenting. This is an important aspect, considering that vaccinating adolescents (who wish so) would allow they to acquire the immune response they could not develop during childhood, as their parents refused to vaccinate them 24,25 .

Such context of vaccination is an important and complex medico-legal problem, as (often) parents must consent for any medical act to be performed on a minor. Until 2017, in Italy, minor's consent had no legal value; so, for vaccination, especially if not mandatory, the adolescent required parental consent. In 2017, when the Italian government promulgated the Law n. 219 (Provisions for informed consent and advance directives) 26, the minor's opinion regarding the performance of a medical act became particularly important. The article 3 states that a parent or legal guardian should accept or refuse the minor's medical treatment considering their will, age, and maturity, and that the ultimate aim must be to protect minor's mental and physical health and life.

This law introduced two basic concepts regarding minor's right to health: first, their will is essential for determining whether or not to undergo a health treatment; second, any decision ultimate aim must be to protect the minor's health and life.

The practical application of this law to the medical act of vaccination means to say that if a teenager decides to get vaccinated and his parents disagree, the minor's will shall prevail.

Italy is not the only country where children and adolescents vaccination is mandatory regardless of parental consent. California (USA), for example, approved in 2015 the Senate Bill 277, removing personal belief as a reason for exemption from vaccination requirements for school entry. Although a relatively simple public health strategy, this bill increased, in 2 years, $5.2 \%$ vaccine coverage 27 . Brazil is another nation where vaccinating children and adolescents is an obligation. In this country, parents that fail in providing children and adolescents with all the mandatory vaccinations - as vaccines are considered a child's and adolescent's right (right to health) - can be reported to guardian council 28. A study analyzing vaccine coverage in Brazil from 2001 to 2011 reported that the 95\% goal was achieved 
for all mandatory vaccinations, except for hepatitis B (2001 to 2005) and rotavirus vaccine (2007 to 2011) 29. Brazil also presents satisfactory levels of vaccine confidence 4.

Vaccination is a right. Minors, if they consent, they have the right to get vaccinated; and a community has the right to protect itself from potential epidemics.

Although parental consent is usually required, we must recognize that, in some situations, medical acts benefit not only the individual, but also the entire community. This is a fundamental concept because, considering minor's mandatory vaccination, it is often stated that vaccination cannot be performed if parents do not consent. But there are certain contexts, such as the Involuntary Health Treatment (IHT) of psychiatric patients with hetero-aggressive behaviors, in which mandatory medical acts (although without consent) aim to safeguard public health.

Regarding vaccines deemed as "mandatory" in many countries worldwide, they serve, firstly, as an instrument of public health and, only in second instance, as a medical act concerning an individual's well-being. Processes that hinder vaccination risk the life not only of a single individual, but the whole community. No evidence-based proofs testify the harmful potential of commonly used vaccines. Some cases of vaccination that meet the irrational refusal of parents would possibly require resorting to a tutelary judge, who may authorize vaccination even when parents refuse to consent and the child/adolescent does not explicitly express consent. The principle - resuming the medico-legal point of view of mandatory vaccination - is that individual's rights end where community's rights begin.

As the improving vaccination coverage in Italy after 2017 has shown, making certain vaccines mandatory by law is an effective medium-term strategy in countries where vaccination coverage is alarmingly declining. Yet, a legislation alone is not enough to improve immunization rates 30 . Anti-vax movements are still particularly strong in Italy; many Italian parents doubt the efficacy and safety of vaccination, and some perceive its compulsory requirement as a coercive measure. Despite the legal responsibility in vaccinating children and adolescents, the government must also adopt an information policy to improve vaccination knowledge among individuals. Then training health professionals to inform and clarify the doubts of hesitant parents regarding vaccines is an essential measure. This is a particularly important point, considering that if doctors fail in adequately supporting doubtful and concerned parents, those might consider pseudo-scientific sources, becoming vulnerable to fake news and scientific misinformation - particularly prolific in the vaccine field.

\section{Additional information}

ORCID: Andrea Cioffi (0000-0001-5163-9558).

\section{References}

1. Legge 31 luglio 2017, n. 119. Conversione in legge, con modificazioni, del decreto-legge 7 giugno 2017, n. 73, recante disposizioni urgenti in materia di prevenzione vaccinale. Gazzetta Ufficiale della Repubblica Italiana 2017; 5 aug.

2. Bechini A, Boccalini S, Ninci A, Zanobini $P$, Sartor G, Bonaccorsi G, et al. Childhood vaccination coverage in Europe: impact of different public health policies. Expert Rev Vaccines 2019; 18:693-701.

3. Bonanni P, Ferro A, Guerra R, Iannazzo S, Odone A, Pompa MG, et al. Vaccine coverage in Italy and assessment of the 2012-2014 National Immunization Prevention Plan. Epidemiol Prev 2015; 39(4 Suppl 1):146-58.

4. Larson HJ, de Figueiredo A, Xiahong Z, Schulz WS, Verger P, Johnson IG, et al. The state of vaccine confidence 2016: global insights through a 67 -country survey. EBioMedicine 2016; 12:295-301.
5. World Health Organization Regional Office for Europe. European Vaccine Action Plan 2015-2020. http://www.euro.who.int/en/ health-topics/disease-prevention/vaccinesand-immunization/publications/2014/euro pean-vaccine-action-plan-20152020-2014.

6. Hickler B, Guirguis S, Obregon R. Vaccine special issue on vaccine hesitancy. Vaccine 2015; 33:4155-6.

7. John TJ, Samuel R. Herd immunity and herd effect: new insights and definitions. Eur J Epidemiol 2000; 16:601-6.

8. European Centre for Disease Prevention and Control. Vaccination coverage for the second dose of measles-containing vaccine by country, 2016, WHO, EU/EEA countries. https:// www.ecdc.europa.eu/en/publications-data/ vaccination-coverage-second-dose-measlescontaining-vaccine-country-2016-who-4. 
9. D’Ancona F, D’Amario C, Maraglino F, Rezza G, Ricciardi W, Iannazzo S. Introduction of new and reinforcement of existing compulsory vaccinations in Italy: first evaluation of the impact on vaccination coverage in 2017 . Euro Surveill 2018; 23:1800238.

10. Vaccine goal achieved, 95\% coverage - ISS. Ansa News 2018; 12 mar. http://www.ansa. it/english/news/2018/03/12/vaccine-goalachieved-95-coverage-iss-3_f73aff94-cde54430-b1f9-fe89d5248b44.html.

11. Ordine Nazionale Biologi. Vaccini: non basta l'efficacia, ci vuole anche la sicurezza. Il Giornale dei Biologi 2018; 8 sep.

12. Leslie DL, Kobre RA, Richmand BJ, Aktan Guloksuz S, Leckman JF. Temporal association of certain neuropsychiatric disorders following vaccination of children and adolescents: a pilot case-control study. Front Psychiatry 2017; 8:3.

13. Wakefield AJ, Murch SH, Anthony A, Linnell J, Casson DM, Malik M, et al. Ileal-lymphoidnodular hyperplasia, non-specific colitis, and pervasive developmental disorder in children. Lancet 1998; 351:637-41.

14. Colafrancesco S, Perricone C, Shoenfeld Y. Autoimmune/inflammatory syndrome induced by adjuvants and Sjögren's syndrome. Isr Med Assoc J 2016; 18:150-3.

15. Inbar R, Weiss R, Tomljenovic L, Arango MT, Deri Y, Shaw CA, et al. Behavioral abnormalities in female mice following administration of aluminum adjuvants and the human papillomavirus (HPV) vaccine Gardasil. Immunol Res 2017; 65:136-49.

16. Centers for Disease Control and Prevention. Vaccine safety publications. https://www.cdc. gov/vaccinesafety/research/publications/in dex.html.

17. Federazione delle Associazioni Italiane degli Informatori Scientifici del Farmaco e del Parafarmaco. I vaccini obbligatori? Manovre delle case farmaceutiche per arricchirsi. https://www.fedaiisf.it/i-vaccini-obbligatorimanovre-delle-case-farmaceutiche-perarricchirsi/.

18. Coordinamento delle Associazioni per la Difesa dell'Ambiente e dei Diritti degli Utenti e dei Consumatori. Vaccini, Ordine medici di Roma: nessuna vaccinazione senza il consenso dei genitori. https://codacons.it/vaccini-ordinemedici-roma-nessuna-vaccinazione-senzaconsenso-dei-genitori/.
19. Patitucci D. Vaccini, il medico radiato Roberto Gava: "Non li rifiuto, ma sono perplesso dalla vaccinazione indiscriminata di massa”. Il Fatto Quotidiano 2017; 5 may. https:// www.ilfattoquotidiano.it/2017/05/05/vacci ni-il-medico-radiato-roberto-gava-non-li-ri fiuto-ma-sono-perplesso-dalla-vaccinazio ne-indiscriminata-di-massa/3561963/.

20. MedNat.News. Herd immunity. https://mednat.news/vaccini/effetto_gregge.htm.

21. EpiCentro. Quali sono le leggende - e le verità - sulle vaccinazioni? https://www.epicentro. iss.it/vaccini/FAQ_Oms_Ita.

22. Pandolfi F, Franza L, Todi L, Carusi V, Centrone M, Buonomo A, et al. The importance of complying with vaccination protocols in developed countries: "anti-vax" hysteria and the spread of severe preventable diseases. Curr Med Chem 2018; 25:6070-81.

23. Signorelli C, Odone A. Four Italian experiences on vaccination policies: results and lessons. Ann Ig 2019; 31(2 Suppl 1):36-44.

24. Immunization of adolescents. Recommendations of the Advisory Committee on Immunization Practices, the American Academy of Pediatrics, the American Academy of Family Physicians, and the American Medical Association. MMWR Recomm Rep 1996; 45(RR13):1-16.

25. Bernstein HH, Bocchini Jr. JA; Committee on Infectious Diseases. The need to optimize adolescent immunization. Pediatrics 2017; 139:e20164186.

26. Legge 22 dicembre 2017, n. 219. Norme in materia di consenso informato e di disposizioni anticipate di trattamento. Gazzetta Ufficiale della Repubblica Italiana 2018; 16 jan.

27. California Department of Public Health. 2016-2017 Kindergarten Immunization Assessment - Executive Summary. http:// eziz.org/assets/docs/shotsforschool/201617KindergartenSummaryReport.pdf.

28. Brazil. Statute of the child and adolescent. Law no 8,069, 13 July 1990. https://www.refworld. org/docid/4c481bcf2.html.

29. Domingues CM, Teixeira AM, Carvalho SM. National immunization program: vaccination, compliance and pharmacovigilance. Rev Inst Med Trop São Paulo 2012; 54 Suppl 18:S22-7.

30. Laws are not the only way to boost immunization. Nature 2018; 553:249-50.
Submitted on $07 /$ Oct/2019

Final version resubmitted on 31/Dec/2019

Approved on 31/Jan/2020 